\title{
EL SENTIMIENTO DE INSEGURIDAD FRENTE A LA \\ SOCIEDAD DE RIESGO: EL PARADIGMA DE LA \\ SEGURIDAD INSEGURA
}

\section{THE FEELING OF INSECURITY FACING THE RISK SOCIETY: THE PARADIGM OF SECURITY UNSAFE}

\section{Ignácio Nunes Fernandes*}

SUMARIO: Introducción; 1. El sentimiento de inseguridad como fenómeno social: el paradigma de la construcción del riesgos; 2. Los nuevos riesgos de una sociedad globalizada; 2.1. Los fenómenos de expansión social; 3.2.El fenómeno de expansión del Derecho Penal; 2.3 ¿Cómo proteger los bienes jurídicos frente a estos nuevos riesgos?; 3. La sociedad de riesgo como espejo de la ineficacia del Derecho Penal clásico. 3.1. ¿El derecho penal del enemigo como único vía para alcanzar los terroristas?; Conclusión; Bibliografía.

RESUMEN: El presente trabajo busca establecer la dicotomía entre la sensación de inseguridad y la sociedad de riesgo como fenómenos socialmente construidos, en el ámbito de la actual sociedad globalizada. Las tendencias principalmente después de los atentados de 11-S llevaran a una sensación de inseguridad general, haciendo que los mecanismos de restricción tomen las medidas necesarias para frenar estos nuevos riesgos. El Derecho penal clásico no está apto a frenar estos nuevos bienes jurídicos y tampoco tiene capacidad de proteger las personas ante los nuevos riesgos, puesto esto surge el debate político criminal de cuño expansionista, o sea el Derecho penal del enemigo como única vía capaz de frenar la delincuencia terrorista. El actual panorama social que estamos sumergidos nos lleva a pensar se necesitamos de un modelo de seguridad a los moldes del Derecho penal del enemigo, o si esta sensación de inseguridad no es sólo aparente. Por fin, la inseguridad es presente, nunca se alcanzará la seguridad completa, por lo tanto debemos elegir a cual margen de inseguridad vamos vivir, la posibilidad de un atentado terrorista o la de un Estado autoritario.

Palabra-clave: Sociedad de riesgo; seguridad; inseguridad; derecho penal del enemigo

\begin{abstract}
This paper seeks to establish the dichotomy between the sense of insecurity and risk society as socially constructed phenomena in the area of today's globalized society. Trends mainly after the attacks of 9/11 lead to a feeling of general insecurity, making restriction mechanisms take the necessarysteps to stop these new risks. The classic criminal law is not fit to stop these new legal rights and has no ability to protect people against the new risks, upon this comes the criminal political expansionist shapeddebate, in other words, criminal law of the enemy as the only means capable of stopping terrorist crime. The current social landscape that we are immersed
\end{abstract}

Mestrando em Derecho penal del MERCOSUR, com orientação em Derechos Humanos y Sistemas Penales Internacionales en la UBA. 
lead us think if we need a security model like enemy criminal law, or if this feeling of insecurity is not only apparent. Finally, insecurity is part of the present, we will never reach full security, so we must choose under which level of insecurity we will live, the possibilityof a terrorist attack or the one of an authoritarian state.

Keys word: Risk society; Security; insecurity; criminal law of enemy

\section{INTRODUCCIÓN}

En este trabajo intentamos establecer cuáles son los nuevos estándares de sociedad actual, bien como todas las tendencias de la sociedad actual, la sociedad globalizada. En este contexto se busca establecer un panorama de los avances de nuestra sociedad, e desarrollo bien como toda la problemática que se crea frente a este crecimiento personal y tecnológico. Con base en esta nueva sociedad surgen los nuevos riesgos, cambios de valores, y el surgimiento de nuevos valores, o mejor diciendo, bienes jurídicos que antes no importaban tanto e ahora son importantes al punto de hacer parte del selecto rol del derecho penal.

Frente a estos nuevos riesgos que compete según algunos al derecho penal proteger surge también la sensación de inseguridad, esta normalmente construida bajo la premisa de que existe un mal en nuestro contexto social y que este debe ser eliminado, o combatido por lo menos. Con relación a todos estos nuevos riesgos al cual de aporta la prensa todos os días, y hechos que siempre ocurrirán se tornan motivo para hacer un sensacionalismo demasiado dejando que buena parte de la sociedad vea que realmente existe un gran mal y que la sociedad está en riesgo. Con esta sensación que está en las calles, en las casas, compete al Estado frenar o combatir este sentimiento, este lo hace por medio del Derecho Penal, en este sentido surgen mecanismos de control social nuevos que no teníamos antes. La expansión del derecho penal no lleva al máximo de contestar se las garantías mínimas, nuestros derechos pueden ser relativizados en beneficio de un bien más grande.

Con los fenómenos de expansión que vamos analizar de forma general en este trabajo existe como grande exponente de la política criminal actual que es el derecho penal del enemigo que es lo máximo de la lucha contra la criminalidad organizada, la lucha contra el terrorismo, narcotráfico, y los demás delitos que pongan la sociedad bajo riesgo.

Sin embargo lo derecho penal clásico no es eficaz frente a esta nueva clase de delincuentes organizados y bien estructurados, es necesario que tengamos un sistema rápido, preventivo y que sea además 
de todo preventivo, nadie quiere otro 11 de septiembre. Pero el terrorismo es un hecho reprochable y compartimos esto así como básicamente todas las democracias del mundo lo reprochan. ¿Todavía aun así me pregunto, este es lo mejor que tenemos para combatirlo?

¿Los Estados crean mecanismos de control y vigilancia para prevenir los delitos de terrorismo e para amenizar la sensación de inseguridad, pero a qué precio? Esta sensación de inseguridad por lo cual todos hablan realmente es una situación donde el Estado debe poner toda su atención para solucionar ese mal que circunda toda la sociedades democráticas del mundo o es solo un miedo generado por medios que tienen intereses subjetivos, que por medio de este miedo, controlan las personas de una forma más sencilla y conveniente en el sentido de que el miedo genera falta de censo crítico para analizar las cosas a fondo e ver si realmente estamos bajo este miedo o es solamente una sensación de inseguridad que puede ser frenada con orientación para calmar los ánimos de la sociedad.

Por fin la sociedad actual frente a lo modelo de derecho penal clásico, sus mecanismos de control frente a las nuevas tendencias, generando la creación de otros mecanismos de control porque este no sirve más, no atiende a las necesidades actuales de nuestra sociedad. Frente a esto, los problemas, las debilidades de nuestro sistema penal clásico, frente a lo que vive hoy y lo que necesita de inmediato nuestra compleja sociedad globalizada. Bien como buscar el censo de equilibrio e cuestionar se preferimos una sociedad tutelada por el derecho penal clásico con un mínimo de garantías, o se las entregamos para el Estado en cambio de una seguridad "total".

\section{EL SENTIMIENTO DE INSEGURIDAD COMO FENÓMENO SOCIAL: EL PARADIGMA DE LA CONSTRUCCIÓN DE RIESGOS}

Siempre se escucha por los medios periodísticos que la inseguridad aumenta a cada día en nuestro contexto social. Que la delincuencia es un fenómeno social pero que cabe al Estado por sus medios combatir esa delincuencia ${ }^{1}$ con leyes más rigurosas, lo que

\footnotetext{
1 "Lo que la población demanda son actuaciones enérgicas contra la delincuencia clásica, la que nace en los aledaños de la desocialización y la marginación, sectores sociales respecto a los que, además, se ha producido un notable desapego y desinterés
} 
incurre a veces a ciertos abusos por parte del poder policial gracias a la aprobación de leyes con ciertos requintes de los antiguos sistemas autoritarios $^{2}$. En este sentido CorneliusPrittwitzseñala que:

por parte de las clases sociales medias mayoritarias; las exigencias de actuación sobre la delincuencia de los poderosos, sin desaparecer, ocupan un lugar secundario y, desde luego, no se percibe entre esas clases medias una pérdida del encanto que le producen los sectores sociales privilegiados y su pautas de comportamiento." (DÍEZ RIPOLLÉS, José Luis, De la sociedad del riesgo a la seguridad ciudadana: un debate desenfocado, Revista Electrónica de Ciencia Penal y Criminología, RECPC 07-01, pp. 1-37, 2005, disponible en criminet.ugr.es

${ }^{2}$ Los ejemplos son los más diversos: La política criminal del fascismo tenía como base la severidad al combate de la delincuencia en nombre de la defensa del Estado, y lo institutos de la prevención, una forma más moderna y adecuada de combatir la delincuencia. (DAL RI JÚNIOR, Arno, O Estado e seus inimigos: a repressão política na história do direito penal, Editora Revan, 2006, p.225). "A democracia é um regime fraco, incapaz de resolver a crise econômica. Os políticos são uma corja de demagogos e corruptos. O que o pais precisa é de um grande líder patriótico, com autoridade incontestável, que acabe com a baderna promovida pelos grevistas, agitadores de esquerda, criminosos e vagabundos”. (SHMIDT, Mario Furley, Nova História Crítica, $2^{\circ}$ ed. Editora Nova Geração, São Paulo. p. 128).

A escola de Kiel apresentava o direito como instrumento e ordenação da vida social, legitimado pelo espírito do povo. O sentimento de Fuhrer deveria preponderar sobre o próprio direito, já que o dirigente estatal catalisava toda a vontade do povo alemão. $\mathrm{O}$ magistrado segundo tal escola poderia, e deveria julgar segundo critérios metájuridicos, isto é, não se encontrava totalmente jungido às leis, o que autorizava o recurso ao "são sentimento do povo" para punir. (DAL RI JÚNIOR, O Estado e seus inimigos..., op. cit., 2006, pp. 246, 247). "O código moscovita assim fixara o princípio do direito penal desprendido das leis: "se uma ação qualquer, considerada socialmente perigosa, não acha especialmente prevista no presente código, os limites e fundamentos da responsabilidade se deduzem dos artigos deste código que prevejam delitos de índole mais análoga". (HUNGRIA, Nélson, Comentários ao Código Penal, $4^{\circ}$ ed., Editora, Forense, 1958, p.15). “A motivação, ou até mesmo a escusa para a repressão política, é delineada na Exposição de motivos da Lei n'. 2.008 de 1926, intitulada 'Provvedimenti per ladifesadelloEstato', peça central na nova política elaborada por Alfredo Rocco. O programa de governo era simples: com uma reforma radical na legislação, pretendia-se criar uma nova ordem jurídica, apta a reforçar a autoridade do Estado e a defendê-lo contra tentativas de prepotência dos indivíduos, dos grupos, das classes, dos partidos (...) Mas a irredutível ignorância de alguns inimigos do fascismo ameaça tornar vão este propósito e jogar, ainda uma vez a Itália na desordem e no turbamento". (DAL RI JÚNIOR, $O$ Estado e seus inimigos..., op., cit.). En Brasil, “A Lei de Segurança Nacional (LSN) promulgada em 1935 definia os crimes contra a ordem política e social. Sua principal finalidade era transferir para uma legislação especial os crimes contra a segurança do Estado, submetendo-os a um regime mais rigoroso, com o abandono das garantias processuais". (DAL RI JÚNIOR, O Estado e seusinimigos..., op. cit., p. 268) Los ideales de la Ley de Seguridad Nacional si implantó en lo continente 
Não se pode com o direito penal, resolver todos os problemas, talvez nem mesmo muitos, talvez apenas alguns problemas específicos, pelo contrário, pode-se até intensificar os problemas que se pretende resolver por meio do direito penal, devido à aplicação muito frequente, muito rígida ou incorreta do direito penal ${ }^{3}$.

En otras palabras interpretando la reflexión del profesor alemán es que el derecho penal es la última ratio y no la solución para problemas sociales, lo que normalmente la sociedad pide es protección, pero la imposición de un derecho penal fuerte, en las palabras de Ferrajoli, un

Latinoamericano desde la guerra de la Argelia, expuesta por autores franceses y por militares norteamericanos. Para los franceses de Argelia "o delito comum deve ser castigado severamente porque é necessário reforçar o máximo a frente interna,” para Durkheim "o delinquente comum é o inimigo interno, do mesmo modo que o soldado é o inimigo externo na guerra", para Garofalo, "em qualquer caso deve-se retribuir o mal do delito, haja ou não necessidade de periculosidade, porque isto é necessário por si mesmo (argumento Kantiano ou absoluto)". (ZAFFARONI, Eugenio Raúl e PIERANGELI, José Henrique, Manual de Direito Penal Brasileiro, V. 1 Parte Geral, $7^{\mathrm{a}}$ ed. Editora RT, 2007, p. 313).

La actual configuración del sistema penal proviene de los albores de la revolución mercantil, de la formación de los estados nacionales, lo que da lugar a la desaparición de los viejos mecanismos de solución de conflictos entre partes enfrentadas, produciéndose la expropiación de los conflictos (derechos de la víctima), asumiendo el lugar de 'única víctima' el 'soberano' y convirtiendo a todo el sistema penal en un ejercicio de poder verticalizante y centralizador. (ZAFFARONI, Eugenio Raúl, En busca de las penas perdidas: deslegitimación y dogmática jurídico-penal, editora Ediar, Buenos Aires, 2009, p. 156). En estos tiempos el objetivo era la seguridad del Soberano $\mathrm{y}$, el mantenimiento de la orden por medio de penas crueles y muy severas siempre buscando la intimidación. (MAGALHÃES NORONHA, E.,Direito penal, parte geral, $8^{\mathrm{a}}$ Ed., Editora Saraiva, 1972, p. 22). La consecuencia del reconocimiento de la venganza por parte del poder público implica en una medida de agresión cuya fórmula es la ley del talión, ojo por ojo, diente por diente. La aplicación de tal interpretación imponía penas brutales contra personas con base en intereses normalmente particulares. (BRUNO, Anibal, Direito Penal, parte geral, tomo I, Editora Forense, $3^{\mathrm{a}}$ Ed., 1967, p.58). La venganza pública surge en el contexto del Estado para mantener la seguridad nacional con identidad estrictamente política y religiosa. (BITENCOURT, Cezar Roberto, Tratado de direito penal, V. 1, parte geral, 10ª Ed., Editora Saraiva, 2006, p.37).

${ }^{3}$ PRITTWITZ, Cornelius, Direito Penal entre Direito Penal do Risco e Direito Penal do Inimigo, Revista brasileira de ciências criminais, no . 47, Editora RT, 2004. 
derecho penal máximo ${ }^{4}$ es buscar aún más inseguridad. Sin embargo se debe tener en cuenta es que los niveles de delincuencia comparados con los niveles de desigualdad social son aún bajos.

Hay que considerar las situaciones con prudencia, un análisis más crítico do que desesperado de la situación ${ }^{5}$ y constatar que los temores de nuestra sociedad actual fueron los mismos en diversos momentos históricos, es decir, la tensión por un miedo de alguien o por un sistema de gobierno $^{6}$.El miedo de cambiar en general conlleva al pánico, principalmente cuando no hay interés en cambiar o el Estado tiene ganas de ampliar sus poderes ${ }^{7}$. Es preciso tenersensibilidad para no empeorarlas cosas, como plantea Julian Marías "O importante é refletir à altura do nosso tempo; isto quer dizer, apropiando-nos da 'circunstância' em que estamos imersos, para reenquadrá-la, num plano superior, que nos liberte da sua prisão lógica",

4 En este sentido Ferrajoli,..."el modelo de derecho penal máximo, es decir, incondicionado e ilimitado, es el que se caracteriza, además de por su excesiva severidad, por la incertidumbre y la imprevisibilidad de las condenas y de las penas; y que consiguientemente, se configura como un sistema de poder no controlable racionalmente por ausencia de parámetros ciertos y racionales de convalidación y de anulación". (FERRAJOLI, Luigi, Derecho y Razón. Teoría del garantismo penal, editorial Trotta, 2009, p. 104).

${ }^{5}$ En este sentido yadecíaHobsbawm: "O terrorismo pede cabeça fria, e não histeria". (HOBSBAWM, Eric, Globalização, democracia e terrorismo, trad. José Viegas, Editora Cia das letras, São Paulo, 2007, p. 46)

${ }^{6} \mathrm{El}$ gran temor del comunismo, la excusa de los militares en los golpes de Estado en Latinoamérica fue el comunismo, la persecución a los estudiantes "comunistas" que en la época eran considerados como "terroristas" que ponían en riesgo el orden del Estado eran presos, torturados, eliminados. Fue una época oscura de miedo y inseguridad. ¿Hoy que mal hace un comunista?

Lo que cabe aclarar es que así como el comunismo, otros tantos son fijados como amenazadores de la paz pública.

7"Desde sua própria origem, o poder punitivo mostrou uma formidável capacidade de perversão, montada (como sempre) sobre um preconceito que impõe medo, neste caso a velha crença vulgar europeia nos maleficia das bruxas, admitida e ratificada abertamente pelos acadêmicos de seu tempo". (ZAFFARONI, Eugenio Raúl, O Inimigo no Direito Penal, Trad. Sérgio Lamarão, ed. Revan, 2007, p. 34).

${ }^{8}$ JULIAN MARÍAS, Ortega, apud, LYRA FILHO, Roberto, Criminologiadialética, Editor Borsoi, 1972, p. 26. 


\section{LOS NUEVOS RIESGOS DE UNA SOCIEDAD GLOBALIZADA}

El derecho penal clásico no alcanza resolver los problemas de las sociedades modernas, los fenómenos de la globalización ${ }^{9}$ y nuevos bienes jurídicos ${ }^{10}$ llevaran a la concepción de nuevos paradigmas tanto en

${ }^{9}$ Para un análisis más específico véase:SILVA SÁNCHEZ, Jesús María, La expansión
del derecho penal: Aspectos de la política criminal en las sociedades postindustriales,
$2^{\mathrm{a}}$ Ed., Editora Civitas, Madrid, 2001 .
${ }^{10}$ Con respecto a los nuevos bienes jurídicos cabe antes señalar cuál es la importancia del bien jurídico y como hacer el análisis para la aplicación de leyes que visan proteger estos bienes, con relación a esto se presente el debate entre Roxin y Jakobs. Claus Roxin afirma que el Derecho Penal tiene la función constitucional de proteger los bienes jurídicos más importantes para mantener el equilibrio social. Sin embargo para Roxin los valores y los criterios sobre conducta punible o no se queda a cargo de la política criminal, ella que, con base en datos empíricos y no meramente el respeto de la norma tiene la capacidad de decir si tales conductas producen daño a bienes jurídicos tutelados por el Derecho Penal, bien como los valores de tales bienes jurídicos. El autor aún expone que la política criminal no es cualquier política criminal, desde una política criminal de Derecho Penal máximo o una política criminal abolicionista. Roxin habla de una política criminal de un Estado Democrático de Derecho, con base en las garantías y los derechos fundamentales asegurados en la Constitución. Los valores están establecidos en la Constitución y, con ese grado de valores trabaja la política criminal con base en datos empíricos buscando siempre adecuar situaciones menos gravosas y más eficaces para las situaciones de hecho.

Mientras que Roxin atribuye la política criminal como base para el valor del bien jurídico, GüntherJakobs aclara que el simple hecho de cometer un delito es lo motivo de la aplicación de una sanción penal. Para Jakobs el Derecho Penal sirve como medio para garantizar, reforzar la norma y volver al equilibrio del contrato. El comportamiento contrario a la norma perturba la paz de todos los ciudadanos, la sanción penal debe incidir sobre el violador de la norma para reafirmar la prevalencia del derecho y de la norma para todos los miembros de la sociedad.

Hay también teorías como la de FrischTeoría del comportamiento típico y las teorías de PuppeTeoría de la causalidad y de la imputación, para un análisis más específico sobre la discusión de la imputación objetiva. (ROXIN, Claus, Funcionalismo e imputação objetiva no Direito Penal, Trad. e int. Luís Greco, Editora Renovar, 2002, pp. 68, 79, 121, 122).

Bajo el debate de cómo proteger los bienes jurídicos clásicos, contemplados por el derecho penal clásico ahora presentamos lo que serían los nuevos bienes jurídicos antes no conocidos, o no considerados a punto de hacer parte del rol normativo del derecho penal, lo que hay hoy por hoy son el medio ambiente como bien jurídico más importante, pero también bienes jurídicos abstractos, los más relevantes y en contante cambio en la sociedad globalizada, los delitos informáticos. Nuevos tipos penales que ponen riesgo desde el patrimonio individual de una persona hacia la seguridad del Estado. ¿Lo gran problema es como el derecho penal debe tutelar estos nuevos tipos 
el ámbito de la tutela penal bien como en el ámbito de la propia concepción social del siglo XXI. Frente esa problemática en constante transformación se contesta los mecanismos de control social, llevando a teorías sobre la expansión o sistemas alternativos del derecho penal en tendencias de derecho penal máximo y derecho penal mínimo a veces habiendo la mezcla de los dos sistemas con base en tendencias de nivel máximo de control o nivel mínimo de control ${ }^{11}$.

\subsection{Los fenómenos de expansión social}

Es considerable el cambio de las sociedades en este siglo, la velocidad de información, el adviento de la internet, digo internet con acceso a todas las personas, tal recurso accesible a todos llevando la información por medio de periódicos electrónicos, o redes sociales. La gran revolución social en este siglo si puede decir que es la comunicación, la capacidad de comunicarse con cualquier otra persona en cualquier parte del mundo, esto lleva a una concepción de mundo nueva. Con base en ese encortamiento de las concepciones de mundo y personas, también las concepciones de sociedad ha cambiado de forma considerable, antes lo que pasaba en determinado país como por ejemplo Libia casi no se escuchaba, porque los únicos medios de información eran los periódicos locales y la televisión, esto para las clases que tenían estos recursos. La gran revolución es la noticia que pasa de persona para persona y no del medio periodístico para las personas. Hay que considerar que la primera noticia de la invasión a la casa de Bin Laden se hizo por Twitter y no por la CNN. Esto cambia totalmente las exigencias sociales frente a la protección social. Sin embargo si esta tecnología es buena por un lado puede ser maligna por otro, es decir la capacidad de

penales? Y otro punto importante es, ¿cabe al derecho penal la tutela de todos los nuevos bienes jurídicos que surgen?

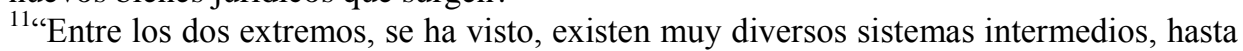
el punto de que debería hablarse más propiamente, a propósito de las instituciones y ordenamientos concretos, de tendencia al derecho mínimo o de tendencia al derecho penal máximo. En los dos ordenamientos de los modernos estados de derecho, caracterizados por la diferenciación en varios niveles de normas, estas dos tendencias opuestas conviven entre sí, caracterizando una a los niveles normativos superiores y la otra a los niveles normativos inferiores, y dando lugar, con su separación, a una inefectividad tendencial de los primeros y a una ilegitimidad tendencial de los segundos”. (FERRAJOLI, Luigi, Derecho y Razón. Teoría del garantismo penal,op. cit., p. 104). 
cometer delitos por internet y al mismo tiempo la velocidad con que estos hechos ocurren en distintas partes del globo hace con que la sensación de inseguridad a nivel global crezca mucho.

\subsection{El fenómeno de expansión del Derecho Penal}

El siglo XXI marca la era de expansión máxima de la sociedad en termos de comunicación, como ya vimos las fronteras de la comunicación terminaran después de la internet, cualquiera habla o hace transacciones, negocios de su propia computadora y como también ya hablamos, con toda esa tecnología y avanzo viene los problemas, la delincuencia globalizada, una delincuencia sin fronteras. Frente a esa delincuencia el tradicional sistema penal clásico no está preparado para frenar estos hechos, no hay todavía tipificados algunos de estos hechos, y más allá de todo existen problemas que aún no se tiene respuesta, situaciones donde la dogmática penal y la política criminal buscan soluciones para la aplicabilidad de tipos penales que son creados bajo una situación de emergencia frente a hechos que ocurren y que no están tipificados $^{12}$. Sin embargo no están tipificados pero el único medio de restricción de derechos eficaz, o por lo menos frente a los demás se parece como medio más eficaz es el derecho penal, y por más que no tenga los medios adecuados, es él lo que debe imponer sanciones para esa nueva clase que surge. ¿Con esa imposición de nuevas responsabilidades ciertos cuestionamientos surgen frente la eficacia del derecho penal con relación a delitos que ya existen bajo la tutela del derecho penal y los nuevos, si estos deben hacer parte del selecto grupo de la última ratio o debe quedarse bajo otro conjunto normativo ${ }^{13}$ ? Para Luhmann:

\footnotetext{
${ }^{12}$ Son los casos de los delitos informáticos, todavía buena parte de estos delitos ya están tipificados en el código penal como por ejemplo la estafa, hurto, derecho del autor, derecho de imagen, etc. Sin embargo la misma situación el tradicional código penal no está preparado, por ejemplo para aplicar la ley al hecho donde los actos preparatorios empiezan en un país pero terminan en otro. O en otro caso, dos sujetos cometen el mismo delito por medio de computadoras distintas, cada cual en su país, pero el hecho resulta en un tercero país. Estos problemas espaciales el derecho penal clásico no está preparado para resolver.

${ }^{13}$ En este sentido cabe aclarar el buen raciocinio que hace NiklasLuhmann que es "toda buena teoría plantea más problemas de los que resuelve. (LUHMANN, Niklas, apud, ZOLO, Danilo,Autopoiesis: crítica de un paradigma posmoderno, Revista Zona abierta, (70-71), 1995, pp. 203-262).
} 
La crisis de la capacidad reguladora del instrumento jurídico en las sociedades posindustriales, la inflación del derecho en las sociedades complejas, la exigencia de una regulación descentralizada de los subsistemas sociales, la tutela de la autonomía del sistema jurídico de la interferencia de otros subsistemas. ${ }^{14}$

Siguiendo en esa idea de regulación descentralizada algunos autores partidarios de la corriente del derecho penal mínimo lanzaran la propuesta de reducción de las tutelas del derecho penal. Este ya no alcanza resolver todos los problemas que sobre él recae, con base en esto la idea es reducir el derecho penal al grupo muy selecto de tipos para que tenga este una buena eficacia y no solo un carácter simbólico. La propuesta de un Derecho Penal mínimo según AlessandroBaratta es "realizar una articulación programática de la idea de la mínima intervención penal como idea-guía para una política penal a corto y mediano plazo". ${ }^{15}$ Para Baratta la lucha por la aplicabilidad de un Derecho Penal mínimo seria como una adopción de los Derechos Humanos $^{16}$, respetar los Derechos Humanos es adoptar un derecho penal mínimo restricto. Otro exponente que lleva la bandera por un derecho penal mínimo es WinfriedHassemer. Giorgio Marinucci y Emilio Dolcini afirman que para Hassemer el derecho penal debe tutelar solamente el bien jurídico más relevante como la vida, la salud, la libertad personal, el honor, la propiedad y el patrimonio, para él solamente la ofensa de estos bienes pueden causar víctimas de carne y hueso. ${ }^{17}$ Tal premisa tiene la base en el bien jurídico, la importancia de la aplicación de la sanción penal está basada en la ofensa del bien jurídico, una de las bases del Derecho Penal liberal. $^{18}$

Marinucci y Dolcini exponen que según Hassemer los delitos económicos, los delitos tributarios, los delitos ambientales, los delitos en

${ }^{14}$ LUHMANN, Niklas, apud, ZOLO, Danilo,Autopoiesis: crítica de un paradigma posmoderno,op. cit.

15 BARATTA, Alessandro, Criminología y sistema penal, compilación in memorian, director Carlos Alberto Elbert, coordinadora Laura Belloqui, Editorial B de F, 2004, Buenos Aires, p. 299.

${ }^{16}$ BARATTA, Criminología y sistema penal,op. cit.

${ }^{17}$ MIRINUCCI, Giorgio; DOLCINI, Emilio, Derecho penal mínimo y nuevas formas de criminalidad, Revista de Derecho Penal y criminología, 2a época, nº 9, 2002, págs. 147167.

${ }^{18}$ MIRINUCCI; DOLCINI,op. cit. 
materia de estupefacientes, el tráfico internacional de armas entre otros deberían ser excluidos del Derecho Penal. ${ }^{19}$ Para Baratta debería ser excluido del Derecho Penal "la seguridad del trabajo..., la corrupción administrativa, las relaciones entre la mafia y el poder legítimo..., Las graves desviaciones de los órganos militares y de los servicios secretos. ${ }^{20}$ Aún Baratta sostiene que los órganos que actúan en los distintos niveles de organización de la justicia penal jueces, promotores en general trabajan y representan la clase dominante y no toda la sociedad, todo el aparato penal trabaja en beneficio de una porción muy restricta de la sociedad mientras que la mayoría, los más débiles son los que más sufren con la actual organización de toda la estructura penal. Todo ese aparato organizado sirve para legitimar la opresión contra los débiles y legitimar los intereses particulares de la camada opresora de la sociedad. ${ }^{21}$ Para Ferrajoli podría dejar el Derecho Penal también por ejemplo, "los delitos contra la personalidad del Estado como por ejemplo, la banda armada, la asociación terrorista, insurrección armada contra los poderes del Estado, la guerra civil". ${ }^{22}$

Todavía si todos los delitos citados no deben ser tutelados por el Derecho Penal, ¿a quién cabe la tutela de tales delitos? Para Hassemer en el Derecho administrativo deberían quedarse los delitos económicos, contra el medio ambiente..., en general todos los delitos que deberían ser excluidos del Derecho Penal deberían ser tutelados por el Derecho administrativo junto a instrumentos clásicos del Derecho administrativo sancionador alemán, el denominado "derecho de intervención"23.

Sin embargo esta expansión a cargo de los defensores del derecho penal mínimo no deja de ser una evolución del derecho penal, una expansión hacia una tendencia más efectiva y no tan simbólica del derecho penal. Por otro lado existen aquellos que contestan esa reducción

\footnotetext{
${ }^{19}$ MIRINUCCI; DOLCINI,op. cit.

${ }^{20}$ MIRINUCCI; DOLCINI,op. cit.

${ }^{21}$ BARATTA, Criminología y sistema penal,op. cit., p. 301.

${ }^{22}$ MIRINUCCI; DOLCINI,op. cit.

${ }^{23}$ MIRINUCCI; DOLCINI,op. cit; Según Hassemer, “crear un derecho de intervención, que se encontraría a medio camino entre el derecho penal y el derecho administrativo sancionador, entre el derecho civil y el derecho público. Este derecho de intervención sería el encargado de ocuparse de esa nueva criminalidad, la sería admisible que aborda con unas reglas de imputación y unas garantías penales y procesales menos estrictas, lo cual debería acompasarse con la previsión de unas sanciones de menor gravedad que las penales". (DÍEZ RIPOLLÉS, José Luis, De la sociedad del riesgo a la seguridad ciudadana: un debate desenfocado, op. cit.).
} 
de poderes del derecho penal y a él atribuyen todo lo que ya existen pero aun así los nuevos delitos de las sociedades globalizadas, delitos eses que tornan difícil la tipificación por así decir de la forma tradicional, situación peculiar que lleva algunos autores a crear teorías de caza a las brujas, como por ejemplo Jakobs con su derecho penal del enemigo ${ }^{24}$, donde se crea un código penal propio para el enemigo, para el excluido social, en este caso se refleja algunas garantías constitucionales, se persigue sospechosos por delitos contra la integridad del Estado, se abre presupuesto para crear tipos penales que puede si decir conexos al objeto principal que se quiere combatir, como por ejemplo en los casos de los terroristas, junto al problema terrorista que ya existe los legisladores principalmente en España crean más problemas, porque tipifican las asociaciones ilícitas, las organizaciones terroristas, es decir, en la sospecha de ser terrorista una asociación, derecho constitucional asegurado es delito tipificado en el Código Penal español con penas de hasta 8 años de cárcel. En este sentido Manuel Cancio Meliá critica de una forma muy precisa la identificación del injusto penal en los delitos de terrorismo, principalmente en los casos de estos delitos conexos al terrorismo donde no se encuentra injusto alguno. ¿Es decir llegamos al punto tal que se la madre que alimenta su hijo terrorista, está colaborando con el terrorismo? Más allá de delitos tipificados en un código penal existe el derecho natural e inherente al ser humano, como por ejemplo la madre que alimenta su hijo.

¿Por otro lado hay que poner en duda la eficacia del derecho penal e se pregunte se Jakobs tiene razón, estamos frente a una criminalidad organizada, informatizada, que recibe plata por medio de financiadores que acreditan en sus causas y con esa plata explotan predios, matan civiles, hacen exigencias, que garantir para estos sujetos? Como se puede hablar de resocialización para un tipo que se pone una bomba en el cuerpo y está dispuesto a quitar la propia vida. ¿Para ellos debemos realmente mantener el estatus de ciudadano? Vale la pena poner en riesgo la vida de personas de bien, niños, niñas, ancianos por un loco que tiene gana de explotar un predio o un shopping porque no le gusta ciertas cosas, o porque EE.UU mató a tantos en Afganistán o Irak. Bajo estos cuestionamientos quizás Jakobs, un normativista radical creó su

\footnotetext{
${ }^{24}$ JAKOBS, Günther; MELIÁ, Manuel Cancio, Direito Penal do Inimigo, noções e críticas, org. e trad. André Luís Callegari, Nereu José Giacomolli, $3^{\mathrm{a}}$ ed., Editora Livraria do Advogado, 2008.
} 
derecho penal del enemigo para identificar y capturar a cualquiera que intente hacer eso. Muchos lo critican pero varios Estados aplican leyes con rasgos de derecho penal del enemigo y quizás sobre estos cuestionamientos Silva Sánchez se preguntó acerca de la tercera velocidad del derecho penal como derecho penal del enemigo. ¿Una tendencia que negamos pero ya aplicamos? En este sentido Jakobs cita Luhmann que preconiza que:

La dogmática tiene que mostrarse adecuada a la complejidad de la sociedad de su tiempo, lo que es un saludable modo de admitir que, por mayores que sean los refinamientos conceptuales y analíticos que alcance, nunca ha de perder de vista el referente central de la realidad social de la que el derecho surge, y a la que finalmente se ve abocado. ${ }^{25}$

Buscando esta adecuación es que el autor español desarrolla su teoría señalando que el derecho penal obedece una evolución que se desarrolla en tres velocidades, "la primera velocidad se refiere al derecho penal de la cárcel en el que habrían de mantenerse rígidamente los principios político-criminales clásicos, las reglas de imputación y los principios procesales." 26 Por lo tanto sigue el profesor Sánchez con "la segunda velocidad, para los casos en que, por no tratarse ya de la cárcel, sino de penas de privación de derechos o pecuniarias, aquellos principios y reglas podrían experimentar una flexibilización proporcionada a la menor intensidad de la sanción"27. Vuelvo a exponer la pregunta de Sánchez: "la pregunta que hay que plantear, en fin es la de si puede admitirse una 'tercera velocidad' del derecho penal en la que el derecho penal de la cárcel concurra con una amplia relativización de garantías político-criminales, reglas de imputación y criterios procesales". ${ }^{28}$

${ }^{25}$ NAVARRO, Evaristo Pietro,Ciudadanos y Enemigos. GüntherJakobs, de Hegel a Schimitt, Derecho Penal y Política Transnacional, coord. Silvina Bacigalupo e Manuel Cancio Meliá, Ed. Atezier, Barcelona, 2005, p. 51.

${ }^{26}$ SÁNCHEZ, Jesús-María,La expansión del derecho penal ..., op. cit., p. 163.

${ }^{27}$ SÁNCHEZ, La expansión del derecho penal...,op. cit.

${ }^{28}$ SÁNCHEZ, La expansión del derecho penal...,op. cit. 


\section{3 ¿Cómo proteger los bienes jurídicos frente a estos nuevos riesgos?}

Frente a los dos extremos de la expansión del derecho penal aún se busca la solución más eficaz e humana para los problemas de la delincuencia, lo gran interrogante es saber se realmente estamos bajo una sociedad peligrosa o lo que estamos viviendo son exageraciones por parte de los Estados para imponer un control social absoluto para todos, es decir vivir bajo una sociedad totalmente vigilada, con cameras de seguridad en todas las calles, sacando de vez el derecho a la privacidad. Si lo que estamos presenciando es la transformación de una sociedad abandonada por el Estado en sus obligaciones mínimas haciendo que los que tienen más condiciones paguen por seguridad privada dejando la mayoría, los que no tienen fondos para pagar, el caos de una sociedad de riesgos.

Infelizmente lo que citamos en el párrafo anterior con relación a buscar una solución eficaz e humana normalmente no se cumple, eficaz se busca, pero humana se olvida, bajo la premisa de la inseguridad, la sociedad clama por seguridad, e pide medidas de urgencia, como siempre se ha visto en la historia.Para amenizar los ánimos de la sociedad con miedo alguien tiene que pagar, "las personas no son capaces de perdonar aquello que no pueden castigar" ya decía Hannah Arendt. Sin embargo no hay un presunto acusado por crear esta sociedad de riesgo, esta sensación de inseguridad, por lo menos no se tiene la persona o el objeto especifico generador de este nuevo factor social. De una forma general esto no es problema, como se sabe e en nuestro contexto histórico, vimos en varias situaciones el Estado, 'bajo la premisa del 'riesgo' se construye la existencia de los 'otros', los excluidos o por así decir el enemigo que en el caso europeo puede ser los inmigrantes o los desempleados" 29 . Normalmente con la ventaja de la sensación de inseguridad la sociedad no contesta mucho algunos abusos por parte del Estado frente a esta clase de personas permitiendo todo tipo de abuso y violación de derechos por parte del órgano responsable por garantizar estos mismos derechos.

\footnotetext{
${ }^{29}$ DÍEZ RIPOLLÉS, José Luis, De la sociedad del riesgo a la seguridad ciudadana: un debate desenfocado,op. cit.
} 
Este es el gran paradigma de la sensación de inseguridad ${ }^{30}$, el miedo genera pánico, con este surge por parte de la sociedad un pedido desesperado de protección, el Estado no resuelve las cosas en dos días, pero la presión política y económica hace que el judiciario haga algo. Bajo esa presión para resolver problemas de políticas sociales en una semana el Estado hace lo que es más fácil, crea un sujeto responsable por ese temor y lo elimina, normalmente pone como responsable alguien que normalmente la sociedad no le cale bien, pero aunque no les guste estos tiene derechos, en suma con base en esto lo que se hace es una respuesta para la inseguridad. La no resolución del problema, porque se sabe que no se resuelve un problema como ese de la noche para el día, y ahora la sociedad tiene una ley o decreto que restringe aún más sus derechos, consecuencia, más inseguridad.

Por fin lo que cabe es la solución de los problemas de seguridad ciudadana pero nunca olvidando las necesidades básicas de los ciudadanos, y no se permitiendo llevar por los desesperos de un riesgo que todavía no existe, esta tendencia es autodestructiva, y solamente trae más inseguridad, nunca se puede olvidar que pedir más rigor y reducción de garantías para proporcionar una seguridad es aprobar que hagan eso con cualquiera, una ley no distingue raza, inmigrante o natural de este país, una ley amplia que permite poderes incontestables por parte del Estado no es saludable y no condice con una sociedad del siglo XXI, hay que tener el censo crítico y buscar soluciones en los sistemas disponibles, tanto en ámbito social, político y legislativo pero nunca olvidando que todas esas medidas se hacen para todos, y no para beneficiar la voluntad de algunos.

\footnotetext{
30،"En la sociedad se ha difundido un exagerado sentimiento de inseguridad, que no parece guardar exclusiva correspondencia con tales riesgos, sino que se ve potenciado por la intensa cobertura mediática de los sucesos peligrosos o lesivos, por las dificultades con que tropieza al ciudadano medio para comprender el acelerado cambio tecnológico y acompasar su vida cotidiana a él, y por la extendida percepción social de que la moderna sociedad tecnológica conlleva una notable transformación de las relaciones y valores sociales y una significativa reducción de la solidaridad colectiva. En suma, todo ese conjunto de factores activa demandas de intervenciones socioestatales que permitan controlar tales riesgos y aplacar tales temores, y a eso se aplica, entre otros mecanismos sociales, la política criminal. "

(DÍEZ RIPOLLÉS, José Luis, De la sociedad del riesgo a la seguridad ciudadana: un debate desenfocado,op. cit.).
} 


\section{LA SOCIEDAD DE RIESGO COMO ESPEJO DE LA INEFICACIA DEL DERECHO PENAL CLÁSICO}

Lo que ahora escribo parece contradecir lo que escribí en el capítulo anterior pero en la realidad lo que se expuso anteriormente fue lo modelo do deber ser, aquí vamos a exponer el modelo del ser, en la práctica los Estados con el modelo de derecho penal clásico no alcanzan solucionar los problemas de delitos por así decir modernos o los tipos que tienen un mínimo de organización y alta capacidad de destrucción. Los modelos de investigación tradicional no alcanzan la eficacia necesaria para no decir mínima de prevenir la realización de tales delitos, con el surgimiento del nuevo terrorismo, el terrorismo que surge del atentado a los torres gemelas en New York en 2001. Antes de este hecho el terrorismo era una preocupación ya tradicional en algunos países como España, Francia, Italia ${ }^{31}$ y otros $^{32}$. Pero lo que pasa a seguir es una tensión a nivel internacional, tal miedo que generó una preocupación internacional $^{33}$. Bajo esa preocupación internacional surgen nuevos tipos

\footnotetext{
${ }^{31}$ Lo que Cretella Neto expone en este momento histórico es el movimiento anarquista a fines del siglo XIX que llevo a un concepto general de lo que significó el terrorismo en aquellos tiempos que es "actos de agresión contra el Estado". (CRETELLA NETO, José, Terrorismo internacional: combatente sem rosto, inimigo sem pátria, Editora Milenium, 2008, pp. 91-96).
}

${ }^{32}$ España tiene la experiencia del terrorismo hace muchos años con el ETA, por lo tanto otros tantos países luchan contra organizaciones terroristas, como por ejemplo Colombia con las FARC, en el pasado muchos países de Europa lucharan contra el terrorismo del Estado, como Alemania, Italia entre otros. Pero lo que se puede decir es que posterior a los atentados ocurridos en New York, Madrid y Londres, las concepciones de terrorismo cambiaran mucho.

${ }^{33}$ Para que la realidad de hoy tenga eficacia un número considerable de tratados y convenciones se ha aprobado en materia de terrorismo, cabe citar el Consejo de Europa del año 1977 (CANCIO MELIÁ, Los delitos de terrorismo: estructura típica e injusto,op. cit., p. 89; MELO REGHELIN, E., Entre terroristas e inimigos..., Revista Brasileira de ciênciascriminais, $\mathrm{n}^{\mathrm{o}}$, 66, Editora RT, 2007, p. 280; CRETELLA NETO, Terrorismo internacional.., op. cit., p. 366; ZBAR, Agustín, terrorismo internacional y derechos humanos: apuntes para una legislación antiterrorista, $1^{\mathrm{a}}$ ed. Fundación Abravanel, Buenos Aires, 2008, p. 47; DIEZ DE VELASCO, Manuel, Instituciones de derecho internacional público, $16^{\mathrm{a}}$ ed., Editorial Tecnos, Madrid, 2007, p. 884), tal aprobación es de suma importancia en el ámbito jurídico de combate al terrorismo porque como afirma Melo Reghelin contempla la extradición como medio esencial y eficaz de atingir sus objetivos de punición frente a tales hechos. El Consejo de la Unión Europea en 1998 describe un concepto de organización criminal(DÓMINE, Maria Cecilia, El terrorismo internacional,op. cit.,Revista brasileira de ciênciascriminais, $\mathrm{n}^{\mathrm{o}}$ 
de mecanismos de investigación y persecución de presuntos terroristas y el cuestionamiento clave: ¿Quién son los terroristas? ¿Qué hacer con ellos?

Como todavía no se tiene respuesta para ninguna de las dos preguntas lo que hacen es olvidar totalmente los conceptos que discutimos en el capítulo anterior, imponer una restricción de derechos, establecer casi un régimen de excepción. En la realidad los terroristas alcanzaran si objetivo en los países atacados, porque más allá del hecho que fue brutal así como cualquier hecho cometido contra la integridad o la vida de una persona es brutal, pero, lo que me refiero es, lo fin de los terrorista no es sacar la vida de personas, sino causar terror, miedo, la sensación de inseguridad.

Con esto la sociedad se encuentra atrapada entre dos extremos, los terroristas que imponen terror con sus bombas, el Estado impone el terror sometiendo todos bajo sospecha de terroristas. ¿Es decir, para que lado seguir?

La gran verdad en este marco divisor entre el antiguo terrorismo, el terrorismo del Estado común y lo terrorismo de hoy, es que por

75, Editora RT, 2008, p.265), ya la convención de Palermo de las Naciones Unidas en 2000 contempla el carácter financiero como fundamental de una organización criminosa (DÓMINE, Maria Cecilia, El terrorismo internacional,op. cit.) . En el marco normativo de la U.E. el Parlamento Europeo en 2001 adopta revisiones trayendo un punto interesante en el marco de la lucha contra el terrorismo que es la abolición de la extradición (DÓMINE, Maria Cecilia, El terrorismo internacional,op. cit., p. 266.), el caso de la prohibición de la extradición en casos de pena de muerte, torturas o cualquier violación a los DD.HH (CRETELLA NETO, Terrorismo internacional..,op. cit., p., 369). Sin embargo la extinción de la extradición es más un cambio de procedimiento do que propiamente una eliminación de tal conducta. Como afirma Brandariz García "la sustitución de la extradición entre los Estados de la Unión por el procedimiento de la orden de detención y entrega europea, adoptada mediante la Decisión marco del Consejo 2002/584/JAI, de 13/06/2002" (BRANDARIZ GARCÍA, J.A., Política criminal de la exclusión: estudios de Derecho Penal y Criminología, Editorial Comares, 2007, p. 223). Cabe aclarar también la declaración de lucha contra el terrorismo adoptada por el Consejo de Europa en Bruselas en 2004 (DÓMINE, Maria Cecilia, El terrorismo internacional,op. cit., p. 270), y por fin la decisión 671 de 20/09 de 2005 (DÓMINE, Maria Cecilia, El terrorismo internacional,op. cit., p. 271), la cual firma el intercambio de información y cooperación en materia de terrorismo. En el mismo año, pero en 16 de mayo se firma en Varsovia otra convención sobre la prevención al terrorismo, tal convención si pone más allá no admitiendo cualquier tipo de acto terrorista no importando el fundamento, eso es, terrorismo político, religioso, lo que sea (CRETELLA NETO, Terrorismo internacional.., op. cit., p. 369). 
primera vez hubo un atentado o un ataque puede así decir en territorio de los EE.UU ${ }^{34}$, eso cambió totalmente todo el sistema, haciendo que como ya decimos mecanismos de persecución se creara para legitimar la venganza de los EE.UU hacia el oriente medio. Verdad que no solo EE.UU sino que muchos países de Europa adecuaron sus leyes para la persecución de presuntos terroristas.

\section{1 ¿El derecho penal del enemigo como único vía para alcanzar los terroristas?}

En medio a esta tensión de cómo combatir los terroristas surge la discusión de una teoría desarrollada por GüntherJakobs en 1985 denominada Derecho Penal del enemigo ${ }^{35}$. Según Jakobs en Alemanía existía una ruptura del código penal, existiendo un código para ciudadanos y un código para enemigos. Para Jakobs los ciudadanos ${ }^{36}$ que cometen delitos por así decir reparables, no pierden el estatus de ciudadano tienen todas las garantías por parte del Estado mientras que para los enemigos ${ }^{37}$ lo que queda es la pérdida de derechos, Jakobs se

\footnotetext{
${ }^{34}$ En la realidad el 11/09 no fue el primero atentado en EE.UU, hubo un atentado contra el propio WorldTrade Center en 1993, un camión conuna bomba explotó en el estacionamiento de la torre norte matando a siete personas y dejando heridos alrededor de mil e cuarenta y dos personas.Sin embargo lo que me refiero a primero atentado es, un número significativo de personas muertas, un ataque masivo contra la gran potencia, en este nivel se puede decir con seguridad que el 11/09 fue el primero atentado significativo no solo en EE.UU., sino para el mundo.

${ }^{35}$ PRITTWITZ, Cornelius, Direito Penal entre Direito Penal do Risco e Dreito Penal do Inimigo, Revista brasileira de ciências criminais, No. 47, Editora RT, 2004, pp. 31-45; NEUMANN, Ulfrid, Direito penal do inimigo, Revista brasileira de ciências criminais, No. 69, Editora RT, 2007, pp. 156-177; GRECO, Luis, Sobre o chamado direito penal do inimigo, Revista brasileira de ciências criminais, No. 56, Editora RT, 2005, pp. 80112.

36 "O direito penal do cidadão define e sanciona delitos ou infrações normativas realizadas pelos indivíduos de um modo incidental, e normalmente havidos como simples expressão do abuso, por parte de tais indivíduos, das relações sociais em que participam com o seu status de cidadãos, isto é, na sua condição de sujeitos vinculados ao e pelo Direito. O delito de um cidadão não surge como princípio do fim da comunidade ordenada, mas só como desgaste, e como deslize reparável". (GRACIA MARTÍN, Luis, O Horizonte do Finalismo e o Direito Penal do Inimigo. Org. e trad. Luiz Régis Prado e Érika Mendes de Carvalho ed. RT 2007 p. 81).

${ }^{37}$ En este sentido Jakobsconstruyesuteoríacon base en Rousseau que "todo malfeitor, ao atacar o direito social converte-se com seus delitos em rebelde e traidor da pátria; deixa de ser membro dela ao violar suas leis, e até a combate. Então, a conservação do Estado
} 
basa en Kant sosteniendo que el "direito vínculo entre pessoas que são titulares de direitos e deveres, aopasso que a relaçãocom o inimigonão se determina pelo direito, mas pela coação" "38. El Estado olvida cualquier garantía e impone la pena como forma de eliminación del mal, para reforzar la vigencia de la norma ${ }^{39}$ y no el objetivo de tutelar los bienes jurídicos ${ }^{40}$ más importantes, el cumplimiento de la ley restablecer la orden y la paz. Jakobs considera el terrorista como lo más lejano de la esfera ciudadana ${ }^{41}$.

Las críticas a su teoría son claras y muy bien fundamentadas, que el derecho penal del enemigo olvida de las garantías constitucionales, que no hay como establecer una distinción segura de personas y no personas,

é incompatível com a sua; é preciso que um dos dois pereça, e quando se mata o culpado, isso é feito em razão de sua condição de inimigo, e não de cidadão. Os procedimentos, o juízo, são as provas e a declaração de que rompeu o pacto social e de que por conseguinte, já não é membro do Estado. Pois bem, como ele se reconheceu como tal, ao menos no que concerne à residência deve ser separado daquele mediante $o$ desterro, como infrator do pacto, ou mediante a morte, como inimigo público; porque um inimigo assim não é uma pessoa moral, é um homem, e então o direito de guerra consiste em matar o vencido". (GRACIA MARTÍN, Luis, $O$ Horizonte do Finalismo e o Direito Penal do Inimigo, op. cit., p. 98).

${ }^{38}$ JAKOBS, Günther; CANCIO MELIÁ, Manuel,Direito Penal do Inimigo: noções e críticas, org. e trad. André Luís Callegari, Nereu José Giacomolli. $3^{\text {a }}$ ed. Livraria do Advogado, 2008, p. 25.

${ }^{39}$ GüntherJakobs aclara que el simple hecho de cometer un delito es lo motivo de la aplicación de una sanción penal. Para Jakobs el Derecho Penal sirve como medio para garantizar, reforzar la norma y volver al equilibrio del contrato. El comportamiento contrario a la norma perturba la paz de todos los ciudadanos, la sanción penal debe incidir sobre el violador de la norma para reafirmar la prevalencia del derecho y de la norma para todos los miembros de la sociedad. (ROXIN, Claus, Funcionalismo e imputação objetiva no Direito Penal, Trad. e int. Luís Greco, Editora Renovar, 2002, pp. $68,79,121,122)$.

Aún Jakobs sostiene que: "la pena no repara bienes, sino que confirma la identidad normativa de la sociedad. Por ello el Derecho Penal no puede reaccionar frente a un hecho en cuanto quebramiento de la norma. Un quebrantamiento de la norma, a su vez, no es un suceso natural entre seres humanos, sino proceso de comunicación, de expresión de sentido entre personas". (POLAINO NAVARRETE, Miguel; POLAINOORTS, Miguel, Derecho Penal. Modernas bases dogmáticas, editora jurídica Grijley, 2004, Lima, p. 239).

${ }^{40}$ Acerca del bien jurídico, Franz Von Lizt "clasifica los crimines en crimines contra los bienes jurídicos del individuo". (VON LIZT, Franz, apud, HUNGRIA, Nelson; FRAGOSO, Heleno Cláudio, Comentários ao Código Penal, vol. V, $6^{\mathrm{a}}$ ed., Editora Forense, 1981, p. 10).Sobre el bien jurídico, véase nota del pie de página ${ }^{\circ} 10$.

${ }^{41}$ JAKOBS; MELIÁ, direito penal do inimigo, op. cit. p. 21. 
todavía no hay como considerar el hecho de existir una clase no-persona, porque dentro de un Estado democrático de derecho todos son iguales, la clasificación de personas determinando que algunas pueden ser simplemente eliminadas conllevaría a la abolición de Estado democrático de derecho ${ }^{42}$. Que el derecho penal del enemigo es un derecho penal del autor y no de hecho. En general el discurso contra la teoría de Jakobs generó debates muy interesantes e obras excepcionales, sin embargo el autor sigue defendiendo su idea y aún sostiene que un derecho penal del enemigo bien delimitado es más seguro que el propio estado democrático de derecho. ${ }^{43}$

Sin embargo, más allá de los cuestionamientos acerca de la legitimidad del derecho penal del enemigo, lo que se debe considerar es su aplicabilidad en las leyes actuales donde los Estados temen el terrorismo, muchos países ya citados lo aplican pero no lo asumen. Lo gran problema en la práctica es el avance en los criterios de prevención de delitos. Se sabe que hay que buscar los medios necesarios para combatir el terrorismo, pero lo que no se autoriza es poner una sociedad entera bajo sospecha y hacer cualquier cosa bajo la excusa de la seguridad nacional. Ese discurso actual remite a los tiempos oscuros en Latinoamérica de los regímenes de excepción. Otro problema es que debido a esa prevención demasiada se creó una nueva clase de delitos que son los conexos al terrorismo, es decir, los de asociación y organización con grupo terrorista, es decir, en la práctica hoy, bajo la sospecha se puede punir el acto de asociarse, o de organización, derechos estos normalmente garantizados en las constituciones democráticas. La crítica a esa modalidad de delito plantea muy bien Cancio Meliá cuando aborda desde una perspectiva de la teoría del delito la localización del injusto en estos delitos conexos ${ }^{44}$.

En suma, por más defectos técnicos que puede contener determinado ordenamiento jurídico, si hay interés en su aplicabilidad este

\footnotetext{
${ }^{42}$ ZAFFARONI, Eugenio Raúl, O Inimigo no Direito Penal, Trad. Sérgio Lamarão, ed. Revan, 2007, p. 192.

${ }^{43}$ JAKOBS; MELIÁ, direito penal do inimigo, op. cit. p. 49.

44 "No parece posible aproximarse a la estructura de los delitos de terrorismo sin haber examinado previamente en qué consisten- en lo jurídico-penalmente esencial: en su contenido de injusto-las infracciones de mera pertenencia a una organización". (CANCIO MELIÁ, Manuel, Los delitos de terrorismo: estructura típica e injusto, $1^{\mathrm{a}}$ ed., Editorial Reus, 2010, p. 48).
} 
se pone en práctica, aún más cuando se tiene total apoyo por parte de la sociedad en la lucha por más seguridad

\section{CONCLUSIÓN}

Nuestro contexto social ha cambiado de una forma demasiada, en los últimos 20 años creo que nuestro desarrollo tecnológico evolucionó lo que llevábamos 50 años en el siglo XX. Como sostengo, la capacidad de información, la velocidad como las noticias, en general todo es una forma que para la generación de este siglo es una cosa normal, pero para los que tuvieron buena parte de la vida en el siglo pasado, no consiguen entender como un hombre puede hacer compras en el otro lado del mundo de su computadora. Esto para nosotros es normal, pero para ellos no. Y con esta concepción ultrapasada de los tiempos es que nuestras leyes ven estos fenómenos sociales ahí y no saben qué hacer, porque las mismas fueron escritas, su mayoría por lo menos en la mitad del siglo pasado, por más que se haga reformas, su estructura general sigue siendo en la vieja máquina de escribir, y no de la computador moderna que te lleva a cualquier parte del mundo con la internet. Estas concepciones ultrapasadas tenemos que superar, todo nuestro ordenamiento jurídico obedece una interpretación del siglo pasado, una orientación de los viejos que no manejan la computadora.

Sin embargo no se puede ser radical e poner todo lo que tenemos en la basura, hay que interpretar y adecuar nuestros avanzos, y nuestras tecnologías para nuestro beneficio, esto es, hacer buen uso de la tecnología desarrollada por el hombre, por supuesto que esta premisa Kantiana del deber ser, de la máxima del ser humano como buen hombre en el cuerpo social no funciona de forma máxima, siempre hay los tipos que hacen malo uso de las tecnologías. Contra ellos debemos estos preparados, y para ellos hay que adecuar un sistema que los alcance, pero además buscando establecer cuáles son los niveles de inseguridad que vive nuestra sociedad de hoy. Si estos niveles son lo que dice el periódico o el Estado o se esto es un sensacionalismo e una manipulación de información para generar aún más pánico. Creo que en primer lugar debemos establecer en qué situación estamos frente a esta inseguridad.

Posterior a esto, debemos establecer mecanismos adecuados a nuestra realidad y que tengan realmente eficacia y no sea ordenamientos meramente simbólicos. Es decir debemos buscar resolver el problema, pero, además de todo nunca olvidando que por cualquier delito que sea, 
que perseguimos, que tipificamos estamos tratando con personas, y estas tienen derechos, estos que están por encima de los códigos penales o civiles, y que por más desarrollado que estemos, y por más que los viejos que no comprenden más computadoras no estén adecuados a las nuevas tendencias, de una cosa ellos tienen autoridad incontestable para hablar. El concepto de libertad, la libertad es una cosa por la cual nascemos con ella y no tenemos idea do que es no tenerla, los viejos saben lo que es no tener libertad, aún más cuando esta libertad es abolida por quien debería asegurarla. En esta materia los viejos son doctores y es una premisa que por más que vengan a cambiar los viejos sistemas porque estos no sirven más una cosa jamás se puede dejar de lado por parte de los viejos, la libertad. Por más que no alcancemos la seguridad total, "quien pone la seguridad por encima de la libertad se arriesga a perder ambas". Benjamin Franklin.

\section{BIBLIOGRAFÍA}

BARATTA, Alessandro, Criminología y sistema penal, compilación in memorian, director Carlos Alberto Elbert, coordinadora Laura Belloqui, Editorial B de F, 2004, Buenos Aires.

BITENCOURT, Cezar Roberto, Tratado de direito penal, V. 1, parte geral, 10 ${ }^{\text {a }}$ Ed., Editora Saraiva, 2006.

BRANDARIZ GARCÍA, J.A., Política criminal de la exclusión: estudios de Derecho Penal y Criminología, Editorial Comares, 2007.

BRUNO, Anibal, Direito Penal, parte geral, tomo I, Editora Forense, $3^{\text {a }}$ Ed., 1967.

CANCIO MELIÁ, Manuel, Los delitos de terrorismo: estructuratípica e injusto, $1^{\mathrm{a}}$ ed., Editorial Reus, 2010.

CRETELLA NETO, José, Terrorismo internacional: combatente sem rosto, inimigo sem pátria, Editora Milenium, 2008.

DAL RI JÚNIOR, Arno, O Estado e seus inimigos: a repressão política na história do direito penal, Editora Revan, 2006. 
DÍEZ RIPOLLÉS, José Luis, De la sociedad del riesgo a la seguridad ciudadana: un debate desenfocado, Revista Electrónica de Ciencia Penal y Criminología, RECPC 07-01, pp. 1-37, 2005, disponible en criminet.ugr.es

DIEZ DE VELASCO, Manuel, Instituciones de derecho internacional público, 16 $6^{\mathrm{a}}$ ed., Editorial Tecnos, Madrid, 2007.

DÓMINE, Maria Cecilia, El terrorismo internacional, Revista brasileira de ciênciascriminais, $\mathrm{n}^{\circ}$ 75, Editora RT, 2008.

FERRAJOLI, Luigi, Derecho y Razón. Teoría del garantismo penal, editorial Trotta, 2009.

GRACIA MARTÍN, Luis, O Horizonte do Finalismo e o Direito Penal do Inimigo. Org. e trad. Luiz Régis Prado e Érika Mendes de Carvalho ed. RT 2007.

GRECO, Luis, Sobre o chamado direito penal do inimigo, Revista brasileira de ciências criminais, No. 56, Editora RT, 2005.

HOBSBAWM, Eric, Globalização, democracia e terrorismo, trad. José Viegas, Editora Cia das letras, São Paulo, 2007.

HUNGRIA, Nélson, Comentários ao Código Penal, $4^{\circ}$ ed., Editora, Forense, 1958.

HUNGRIA, Nelson; FRAGOSO, Heleno Cláudio, Comentários ao Código Penal, vol. V, 6ª ed., Editora Forense, 1981.

JAKOBS, Günther; MELIÁ, Manuel Cancio, Direito Penal do Inimigo, noções e críticas, org. e trad. André Luís Callegari, Nereu José Giacomolli, $3^{\text {a }}$ ed., Editora Livraria do Advogado, 2008.

LYRA FILHO, Roberto, Criminologia dialética, Editor Borsoi, 1972.

MAGALHÃES NORONHA, E.,Direito penal, parte geral, $8^{\text {a }}$ Ed., Editora Saraiva, 1972. 
MELO REGHELIN, E.,Entre terroristas e inimigos..., Revista Brasileira de ciências criminais, nº, 66, Editora RT, 2007.

MIRINUCCI, Giorgio; DOLCINI, Emilio, Derecho penal mínimo y nuevas formas de criminalidad, Revista de Derecho Penal y criminología, $2^{a}$ época, nº. 9, 2002, págs. 147-167.

NAVARRO, Evaristo Pietro, Ciudadanos y Enemigos. GüntherJakobs, de Hegel a Schimitt, Derecho Penal y Política Transnacional, coord. Silvina Bacigalupo e Manuel CancioMeliá, Ed. Atezier, Barcelona, 2005, p. 51.

NEUMANN, Ulfrid, Direito penal do inimigo, Revista brasileira de ciências criminais, Nº 69, Editora RT, 2007.

POLAINO NAVARRETE, Miguel; POLAINO-ORTS, Miguel, Derecho Penal. Modernas bases dogmáticas, editora jurídica Grijley, 2004, Lima.

PRITTWITZ, Cornelius, Direito Penal entre Direito Penal do Risco e Direito Penal do Inimigo, Revista brasileira de ciências criminais, $\mathrm{n}^{\circ} .47$, Editora RT, 2004.

ROXIN, Claus, Funcionalismo e imputação objetiva no Direito Penal, Trad. e int. Luís Greco, Editora Renovar, 2002.

SILVA SÁNCHEZ, Jesús María, La expansión del derecho penal: Aspectos de la política criminal en las sociedades postindustriales, $2^{\mathrm{a}}$ Ed., Editora Civitas, Madrid,2001.

SHMIDT, Mario Furley, Nova História Crítica, $2^{\circ}$ ed. Editora Nova Geração, São Paulo.

ZAFFARONI, Eugenio Raúl e PIERANGELI, José Henrique, Manual de Direito Penal Brasileiro, V. 1 Parte Geral, 7ª ed. Editora RT, 2007.

ZAFFARONI, Eugenio Raúl, En busca de las penas perdidas: deslegitimación y dogmática jurídico-penal, editora Ediar, Buenos Aires.

ZAFFARONI, Eugenio Raúl, O Inimigo no Direito Penal, Trad. SérgioLamarão, ed. Revan, 2007. 
ZBAR, Agustín, terrorismo internacional y derechos humanos: apuntes para una legislación antiterrorista, $1^{\mathrm{a}}$ ed. Fundación Abravanel, Buenos Aires, 2008.

ZOLO, Danilo,Autopoiesis: crítica de un paradigma posmoderno, Revista Zona abierta, (70-71), 1995, pp. 203-262. 